BMJ Open

Diabetes

Research

$\&$ Care

\title{
Hepatic de novo lipogenesis is suppressed and fat oxidation is increased by omega- 3 fatty acids at the expense of glucose metabolism
}

\author{
Charlotte J Green, ${ }^{1}$ Camilla Pramfalk, ${ }^{1}$ Catriona A Charlton, ${ }^{1}$ Pippa J Gunn, ${ }^{1}$ \\ Thomas Cornfield, ${ }^{1}$ Michael Pavlides, ${ }^{1,2}$ Fredrik Karpe (D) , ${ }^{1,3}$ Leanne Hodson (D) ${ }^{1,3}$
}

To cite: Green CJ, Pramfalk C, Charlton CA, et al. Hepatic de novo lipogenesis is suppressed and fat oxidation is increased by omega-3 fatty acids at the expense of glucose metabolism. BMJ Open Diab Res Care 2020:8:e000871. doi:10.1136/ bmjdrc-2019-000871

- Additional material is published online only. To view please visit the journal online (http://dx.doi.org/10.1136/ bmjdrc-2019-000871).

CJG and CP contributed equally.

Received 31 August 2019 Revised 7 February 2020 Accepted 20 February 2020

Check for updates

(C) Author(s) (or their employer(s)) 2020. Re-use permitted under CC BY. Published by BMJ.

${ }^{1}$ University of $0 x f o r d$, Oxford, UK

${ }^{2}$ Translational Gastroenterology Unit, John Radcliffe Hospital, Oxford, UK

${ }^{3}$ National Institute for Health Research Oxford Biomedical Research Centre, Oxford University Hospitals Foundation Trust, Oxford, UK

Correspondence to Professor Leanne Hodson; leanne.hodson@ocdem.ox. ac.uk

\section{ABSTRACT}

Objective Increased hepatic de novo lipogenesis (DNL) is suggested to be an underlying cause in the development of nonalcoholic fatty liver disease and/or insulin resistance. It is suggested that omega-3 fatty acids (FA) lower hepatic DNL. We investigated the effects of omega-3 FA supplementation on hepatic DNL and FA oxidation using a combination of human in vivo and in vitro studies.

Research design and methods Thirty-eight healthy men were randomized to take either an omega-3 supplement ( $4 \mathrm{~g} /$ day eicosapentaenoic acid (EPA)+docosahexaenoic acid (DHA) as ethyl esters) or placebo ( $4 \mathrm{~g} /$ day olive oil) and fasting measurements were made at baseline and 8 weeks. The metabolic effects of omega-3 FAs on intrahepatocellular triacylglycerol (IHTAG) content, hepatic DNL and FA oxidation were investigated using metabolic substrates labeled with stable-isotope tracers. In vitro studies, using a human liver cell-line was undertaken to gain insight into the intrahepatocellular effects of omega-3 FAs.

Results Fasting plasma TAG concentrations significantly decreased in the omega-3 group and remained unchanged in the placebo group. Eight weeks of omega-3 supplementation significantly decreased IHTAG, fasting and postprandial hepatic DNL while significantly increasing dietary FA oxidation and fasting and postprandial plasma glucose concentrations. In vitro studies supported the in vivo findings of omega-3 FAs (EPA+DHA) decreasing intracellular TAG through a shift in cellular metabolism away from FA esterification toward oxidation.

Conclusions Omega- 3 supplementation had a potent effect on decreasing hepatic DNL and increasing FA oxidation and plasma glucose concentrations. Attenuation of hepatic DNL may be considered advantageous; however, consideration is required as to what the potential excess of nonlipid substrates (eg, glucose) will have on intrahepatic and extrahepatic metabolic pathways.

Trial registration number NCT01936779.

\section{INTRODUCTION}

Nonalcoholic fatty liver disease (NAFLD), defined as excess intrahepatocellular triacylglycerol (IHTAG) accumulation due to nonalcoholic causes, is a complication in individuals who are obese and/or have type

\section{Significance of this study}

What is already known about this subject?

- Supplementation with the marine-derived omega-3 fatty acids, eicosapentaenoic acid and docosahexaenoic acid, significantly decrease plasma triacylglycerol concentrations and may reduce intrahepatic triacylglycerol content.

- Animal and in vitro cellular studies have shown that omega-3 fatty acids have a hepatocyte-specific effect at the level of gene transcription where they co-ordinately downregulate hepatic lipogenesis and upregulate fatty acid oxidation.

What are the new findings?

- Supplementation with omega-3 fatty acids in humans downregulated fasting and postprandial hepatic de novo lipogenesis and increased postprandial fatty acid oxidation.

- We found fasting and postprandial plasma glucose concentrations increased after supplementation with omega- 3 fatty acids.

How might these results change the focus of research or clinical practice?

- When hepatic de novo lipogenesis is attenuated, consideration needs to be given to the impact excess nonlipid substrates may have on other metabolic pathways.

- Understanding how omega-3 fatty acid supplementation may affect hepatic glucose metabolism in humans in vivo remains to be determined.

- Clarifying the impact background diet has on metabolic pathways when humans are supplemented with omega-3 fatty acids.

2 diabetes (T2D). ${ }^{1}$ Increased hepatic de novo lipogenesis (DNL) is often suggested to be an underlying cause in the development of NAFLD and/or insulin resistance. ${ }^{2}$ Observational studies have reported fasting hepatic DNL to be higher in individuals with NAFLD compared with those without. ${ }^{3}{ }^{4}$ It has been suggested that changes in plasma 
TAG concentrations are proportional to the amount of hepatic DNL. ${ }^{5}$

Supplementation with the marine-derived omega-3 fatty acids (FAs), eicosapentaenoic acid (EPA) and docosahexaenoic acid (DHA), in doses of $\geq 3 \mathrm{~g} /$ day significantly decrease plasma TAG concentrations ${ }^{6}$ and can reduce IHTAG content. ${ }^{7}$ In vitro cellular and animal models have proposed the mechanisms by which this is achieved include downregulation of lipogenic and upregulation of $\beta$-oxidation pathways via hepatic transcription factors. ${ }^{7}$ In-line with omega-3 FAs upregulating $\beta$-oxidation, some, ${ }^{8} 9$ but not all, ${ }^{10}$ have reported an increase in fat oxidation, when assessed by indirect calorimetry. However, few have assessed the effect of omega-3 FAs on fasting and postprandial hepatic DNL and FA oxidation, simultaneously, in vivo, in humans.

The effects of omega-3 supplementation on markers of glycemia are inconsistent. For example, Logan $e t a l^{8}$ reported no change in older, overweight/obese females taking $3 \mathrm{~g}$ EPA+DHA for 12 weeks, while others report increased fasting plasma glucose concentrations in individuals with T2D taking $20 \mathrm{~mL}$ fish oil for 9 weeks ${ }^{9}$ or $5 \mathrm{~g}$ EPA+DHA for 24 weeks ${ }^{11}$; in one case, a decrease was reported in overweight/obese adults with impaired glucose tolerance taking $3 \mathrm{~g}$ EPA+DHA for 18 months. ${ }^{12}$ The disparity in findings is likely related to the dose and duration of omega-3 supplementation along with the clinical status of the individuals studied. In a pilot study, we previously found supplementation with $4 \mathrm{~g}$ /day EPA+DHA for 15-18 months in individuals with NAFLD did not alter fasting plasma glucose concentrations, but decreased fasting hepatic DNL and increased plasma 3-hydroxybutryate $(3 \mathrm{OHB})$ concentrations. ${ }^{13}$ Therefore, the aim of this work was to extend our previous observations and investigate the effect of 8 weeks of EPA+DHA (omega-3) supplementation on fasting and postprandial hepatic DNL and FA oxidation using a combination of human in vivo and in vitro models and stable-isotope tracer methodology.

\section{RESEARCH DESIGN AND METHODS}

\section{In vivo human studies}

Healthy male participants, with fasting plasma TAG concentrations $1.5 \mathrm{mmol} / \mathrm{L}$ or greater were recruited from the Oxford BioBank (OBB) ${ }^{14}$ All volunteers were nondiabetic and free from any known disease, had a body mass index $<35 \mathrm{~kg} / \mathrm{m}^{2}$, were not taking medication known to affect lipid or glucose metabolism, did not smoke, did not consume alcohol above recommended limits ${ }^{15}$ and were not taking any supplements enriched with omega-3 FAs.

\section{Study design, randomization and supplementation}

A total of 57 men (aged 35-55 years) were screened with 47 meeting the inclusion criteria. Participants were randomly assigned to consume either omega-3 FA ethyl esters $(4 \mathrm{~g} /$ day, $\mathrm{n}=24)$ or placebo $(4 \mathrm{~g} /$ day, $\mathrm{n}=23)$ and were studied before and 8 weeks after supplementation (online supplementary figure 1). Participants randomized to the omega- 3 FA group consumed $4 \times 1 \mathrm{~g}$ capsules/ day with each capsule containing $460 \mathrm{mg}$ EPA ethyl ester and $380 \mathrm{mg}$ DHA ethyl ester (a total of $1.84 \mathrm{~g} \mathrm{EPA}+1.52 \mathrm{~g}$ DHA/day (medicinal product name Omacor/Lovaza)). Participants randomized to the placebo group consumed $4 \times 1 \mathrm{~g}$ capsules/day with each capsule containing olive oil (FA composition oleic acid $\sim 67 \%$, palmitic acid $\sim 15 \%$, linoleic acid $\sim 15 \%$ and stearic acid $\sim 2 \%$, alpha linolenic acid $\sim 1 \%$ ). This was an open-label study and the dose of $4 \mathrm{~g}$ /day was based on previous studies ${ }^{16}{ }^{17}$ and olive oil was chosen as a placebo as oleic acid is a commonly consumed FA due to its ubiquitous nature in foods ${ }^{18}$ and has been used previously. ${ }^{1017}$ Both the omega-3 and placebo were administrated as $1 \mathrm{~g}$, soft red-brown, gelatin shelled capsules and participants were encouraged to take the supplement with the first meal of the day. Supplements (omega- 3 and placebo) were provided by Pronova BioPharma (now part of BASF) (Pronova BioPharma ASA, Lysaker, Norway).

We determined the 90th percentile of plasma TAG concentrations for males in the $\mathrm{OBB}$ was $2.2 \mathrm{mmol} / \mathrm{L}$ (SD of $0.5 \mathrm{mmol} / \mathrm{L})$. Based on the work of Chan $e t a l,{ }^{19} 20$ who reported a $25 \%$ decrease in plasma TAG, in males after 6 weeks of omega-3 FA supplementation $(4 \mathrm{~g} /$ day EPA+DHA), we predicted a $20 \%$ decrease in plasma TAG after 8 weeks supplementation with $4 \mathrm{~g}$ /day of omega-3 FA. The number of individuals required to detect a $20 \%$ decrease in plasma TAG, with a power of 0.80 and $\alpha$ of 0.05 , was $\mathrm{n}=21$. The supplementation period of 8 weeks was based on the work of Cussons et al. ${ }^{17}$

Whole body composition and fat distribution were measured using dual-energy X-ray absorptiometry ${ }^{21}$ at the baseline visit.

\section{Placebo group}

Of the 23 individuals randomized, 4 did not complete the study due to changes in personal and/or working circumstances, therefore giving complete data for 19 individuals (online supplementary figure 1). Participants came in to the Clinical Research Unit after an overnight fast for fasting blood samples, at the beginning and 8 weeks after supplementation with placebo capsules.

\section{Omega-3 supplementation group}

Of the 24 participants randomized, 3 did not complete the study due to changes in personal and/or working circumstances leaving 21 participants for whom we had fasting data. As we wanted to investigate the effect of omega-3 FAs on hepatic DNL and FA partitioning, only participants in this group had IHTAG measured and underwent postprandial study days. From this, we have complete data for 19 individuals as two individuals did not complete the second postprandial study day due to difficulties in obtaining blood samples over the course of the study day (online supplementary figure 1 ). 


\section{Compliance}

To assess compliance of participants to taking the supplements erythrocyte FA composition was assessed ${ }^{18}$ at baseline and after 8 weeks as described. ${ }^{22}$

\section{Measurement of IHTAG content (omega-3 group only)}

IHTAG content was measured using proton magnetic resonance spectroscopy within 1 week of the metabolic study day, at baseline and after 8 weeks of omega-3 FA supplementation as described. ${ }^{23}$

\section{Metabolic study day (omega-3 group only)}

Prior to the study day, subjects were asked to avoid foods naturally enriched in ${ }^{13} \mathrm{C}$ (eg, cornflakes, popcorn, foods made with corn starch and so on), alcohol and strenuous exercise. The evening prior to the study day, subjects consumed deuterated water $\left({ }^{2} \mathrm{H}_{2} \mathrm{O}\right)(3 \mathrm{~g} / \mathrm{kg}$ body water $)$ and continued to consume ${ }^{2} \mathrm{H}_{2} \mathrm{O}$ during the course of the study day for the measurement of fasting and postprandial hepatic DNL. ${ }^{24}$

On the study day, after an overnight fast and consumption of ${ }^{2} \mathrm{H}_{2} \mathrm{O}$, subjects came to the Clinical Research Unit and a cannula was inserted into an antecubital vein and baseline (Time 0) blood and breathe samples taken. Participants were then fed a mixed test meal, consisting of $40 \mathrm{~g}$ Rice Krispies (Kelloggs, Manchester, UK), $200 \mathrm{~g}$ skimmed milk and a chocolate drink containing $40 \mathrm{~g}$ olive oil ( $40 \mathrm{~g}$ fat, $40 \mathrm{~g}$ carbohydrate). Two hundred $\mathrm{mg}$ of $\left[\mathrm{U}^{13} \mathrm{C}\right]$ palmitic acid was emulsified with the chocolate drink to trace the fate of the dietary FAs. Repeated blood and breath samples were taken over the course of the study period.

Indirect calorimetry was performed at Time 0 (fasting) and then $120 \mathrm{~min}$ after consumption of the test meal using a GEM calorimeter (GEMNutrition, Daresbury, Cheshire, UK) to determine whole-body $\mathrm{CO}_{2}$ production, whole-body respiratory exchange ratio and substrate utilization rates.

\section{Analytical methods}

Whole blood was collected into heparinized syringes (Sarstedt, Leicester, UK) and plasma was rapidly separated by centrifugation at $4^{\circ} \mathrm{C}$ for the measurement of plasma metabolite and insulin concentrations as described. ${ }^{25}$ Separation of the chylomicron fraction ( (Svedberg flotation rate, $\left.S_{f}\right)>400$ ) and the very low-density lipoprotein (VLDL)-rich fraction ( $\left.\mathrm{S}_{\mathrm{f}} 20-400\right)$ were made by sequential flotation using density gradient ultracentrifugation and anti-ApoB100 immunoabsorption capture to obtain a fraction completely devoid of apoB48 and hereafter called VLDL, as described. ${ }^{25}$

Samples were taken at Time 0 (baseline) and then 30 , $60,90,120,180,240,300$ and 360 min after the consumption of the test meal for the measurement of plasma glucose, insulin, TAG, nonesterified fatty acids (NEFA), $3 \mathrm{OHB}$ and at 0, 15, 30, 60, 90, 120, 180, 240, 300 and $360 \mathrm{~min}$ for the analysis of chylomicron-TAG, TAG-rich lipoproteins-TAG and 0, 180, 240, 300 and $360 \mathrm{~min}$ for the analysis of VLDL-TAG. Breath samples were collected at $0,60,90,120,180,240,300$ and $360 \mathrm{~min}$ into EXETAINER tubes (Labco, High Wycombe, Bucks, UK) for measurement of expired ${ }^{13} \mathrm{CO}_{2}$ enrichment.

\section{FA and isotopic enrichment}

To determine the specific FA composition and isotopic enrichment, total lipids were extracted from plasma and lipoproteins. FA methyl esters were prepared from plasma NEFA, and TAG fractions, along with erythrocyte total phospholipids as described. ${ }^{22}$ The FA compositions ( $\mu \mathrm{mol} / 100 \mu \mathrm{mol}$ total FA) in these fractions were determined by gas chromatography (GG) and in plasma NEFA and TAG fractions palmitate concentrations were calculated as described. ${ }^{25}$

$\left[\mathrm{U}^{13} \mathrm{C}\right]$ palmitate enrichments were measured in plasma NEFA, TAG, $\mathrm{S}_{\mathrm{f}}>400$ (chylomicron-TAG), $\mathrm{S}_{\mathrm{f}}$ 20-400-TAG and VLDL-TAG FA methyl ester derivatives using a Delta Plus XP GC-combustion isotope ratio mass spectrometer (Thermo electron, Bremen, Germany). ${ }^{26}$ The tracer-totracee ratio (TTR) of a baseline measurement (before administration of $\left[\mathrm{U}^{13} \mathrm{C}\right]$ palmitate) was subtracted from the TTR of each sample to account for natural abundance and then multiplied by the corresponding palmitate concentrations to give plasma and lipoprotein tracer concentrations. $^{25}$

We estimated dietary FA oxidation at the whole-body and hepatic level. By collecting breath samples relative rate of whole-body meal-derived FA oxidation were calculated as described. ${ }^{26}$ The liver is the only organ to produce urea in significant amounts and $\mathrm{CO}_{2}$ produced from hepatic FA oxidation is used in urea synthesis. ${ }^{27}$ We used stable-isotope methodologies to measure ${ }^{13} \mathrm{CO}_{2} /{ }^{12} \mathrm{CO}_{2}$ ratios liberated from plasma urea, based on the method of Kloppenburg et $a t^{28}$ to assess whether recently ingested dietary FAs were undergoing complete intrahepatic oxidation. To allow for sequestration of label into the bicarbonate pool a dietary acetate recovery factor of $51 \%$ was applied. ${ }^{29}$ Hepatic $\mathrm{CO}_{2}$ production was not measured directly, but calculated using reported splanchnic respiratory quotients. ${ }^{30}$

Fasting and postprandial hepatic DNL was assessed based on the incorporation of deuterium from ${ }^{2} \mathrm{H}_{2} \mathrm{O}$ in plasma water (Finnigan Gas-Bench-II; Thermo Fisher Scientific, Loughborough, UK) into VLDL-TG palmitate using GC-mass spectrometry with monitoring ions with mass-to-charge ratios $(\mathrm{m} / \mathrm{z})$ of $270(\mathrm{M}+0)$ and $271(\mathrm{M}+1)$ and percentage DNL calculated as described. ${ }^{31}$

\section{In vittro cellular studies}

All reagents were obtained from Life Technologies (Paisley, Scotland) unless otherwise stated. Fetal bovine serum (FBS) was purchased from Seralab (West Sussex, UK). FAs were purchased from Cambridge Bioscience (Cambridge, UK). FA free bovine serum albumin (BSA), was purchased from SIGMA Aldrich (UK). KAPA probe fast mix was purchased from KAPA Biosystems (London, $\mathrm{UK})$. 


\section{Cell culture}

Huh7 cells were grown as described. ${ }^{32}$ Confluent cells were cultured in DMEM $(11 \mathrm{mM})+$ Glutamax, $10 \%$ FBS, $1 \times$ nonessential amino acids, $1 \%$ penicillin-streptomycin, for 48 hours prior to FA treatment. Cells were first treated with $100 \mu \mathrm{M}$ FA (containing oleic $(\mathrm{O}, 45 \%)$, palmitic (P, $30 \%$ ) and linoleic (L, 25\%) acid (OPL) conjugated to $0.25 \%$ FA-free BSA giving a FA:BSA molar ratio of 3:1 for 24 hours. Next, the cells were treated with $200 \mu \mathrm{M}$ FA (FA:BSA molar ratios of 3:1) mixtures for 48 hours that consisted of either OPL alone $(90 \mu \mathrm{M}$ oleic, $60 \mu \mathrm{M}$ palmitic and $50 \mu \mathrm{M}$ linoleic acid or OPL+EPA+DHA $(49.5 \mu \mathrm{M}$ oleic, $33 \mu \mathrm{M}$ palmitic, $27.5 \mu \mathrm{M}$ linoleic $+55 \mu \mathrm{M}$ $\mathrm{EPA}+45 \mu \mathrm{M}$ DHA). EPA and DHA stocks were stored under nitrogen and cells and media were collected on ice for TAG measurement, which was quantified as described. ${ }^{32}$ RNA extraction was carried out using QIAGEN RNeasy Mini Kit according to manufacturer's instructions.

\section{FA and isotopic enrichment}

To determine the effect of EPA+DHA on the contribution of DNL-derived FA to intracellular TAG, $50 \%(5.5 \mathrm{mM})$ of media glucose was labeled with $\left[\mathrm{U}^{13} \mathrm{C}\right]$ for 48 hours. Cells were collected for analysis and the contribution of glucose-derived FA in intracellular TAG determined using GC-mass spectrometry as described. ${ }^{33}$

To trace the oxidation of exogenous FA, Huh7 cells were treated with OPL and OPL+EPA+DHA where palmitate was labeled $\left(100 \% \mathrm{D}_{31}\right.$ palmitate) for 48 hours. As a marker of FA oxidation, the appearance of ${ }^{2} \mathrm{H}_{2} \mathrm{O}$ (derived from $\left[\mathrm{D}_{31}\right]$ palmitate) in media was measured, using a Finnigan GasBench-II (ThermoFisher Scientific, UK) ${ }^{34}$

\section{Quantitative real time PCR}

First strand cDNA was synthesized from $0.5 \mu \mathrm{g}$ total RNA using a High Capacity Reverse Transcription kit. RT-PCR reactions were run on an Applied Biosystems 7900HT machine. Two housekeeping genes were used: tyrosine 3-monooxygenase/tryptophan 5-monooxygenase activation protein zeta and beta-2-microglobulin.

\section{Calculations and statistical methods}

Homeostatic model assessment of insulin resistance (HOMA-IR) was calculated. ${ }^{35}$ Data were analyzed using SPSS for Windows V.22 (SPSS, Chertsey, UK). All data are presented as means \pm SEM unless otherwise stated. Areas under the curve (AUCs) were calculated by the trapezoid method. AUCs have been divided by the relevant time period to give time-averaged values. All data sets were tested for normality according to the Shapiro-Wilk test. Comparisons between the placebo and omega-3 groups were made using an independent t-test or Mann Whitney $\mathrm{U}$ tests for nonparametric data. For comparisons within the groups before and after supplementation were made using a students paired t-test or the nonparametric equivalent. Postprandial data were compared using repeated measures analysis of variance, with time and treatment as factors to investigate the change within the omega-3 FA group over time for specific metabolites. Bonferroni posthoc analysis was performed where appropriate to adjust for multiple comparisons. Associations between variables were carried out using Spearman's rank correlation coefficient. Statistical significance was set at $\mathrm{p}<0.05$.

For in vitro cell studies, data were analyzed using GraphPad Prism 7 software using an independent t-test or Mann Whitney U test for nonparametric data (GraphPad software, La Jolla, USA).

\section{RESULTS}

\section{In vivo human study}

\section{Participant characteristics}

Thirty-eight subjects (19 placebo and 19 omega-3) completed the study. There was no difference in age, weight, body mass index or waist circumference between or within the groups at baseline and after 8 weeks (table 1). There was no difference between the groups in body composition, which was assessed at the baseline visit with total fat, lean and visceral fat masses being $26.3 \pm 1.5 \mathrm{~kg}$ vs $27.6 \pm 1.9 \mathrm{~kg}, 60.8 \pm 1.6 \mathrm{~kg}$ vs $60.5 \pm 1.6 \mathrm{~kg}$ and $1.7 \pm 0.1 \mathrm{~kg}$ vs $1.8 \pm 0.2 \mathrm{~kg}$, placebo vs omega- 3 , respectively. Between baseline and 8 weeks fasting plasma TAG and ALT concentrations significantly $(p<0.01)$ decreased, while plasma glucose significantly $(p<0.05)$ increased in the omega-3 group while between the groups the only significant $(\mathrm{p}<0.05)$ difference was the change in plasma TAG and ALT concentrations (table 1).

\section{Compliance}

Compared with the placebo group, there was a significant $(p<0.05)$ increase in erythrocyte EPA, docosapentaenoic acid (DPA) and DHA in the omega-3 group between baseline and 8 weeks (table 1 ). Within the omega- 3 group, there was a graded response with the relative change in erythrocyte EPA content ranging from $69 \%$ to $537 \%$ and the relative change in erythrocyte DHA content was from a small decrease of $-6 \%$ to an increase of $24 \%$. There was a strong inverse association between baseline levels of erythrocyte EPA and the per cent change in EPA achieved $\left(r_{s}=-0.73, p<0.001\right)$ while there was no association between baseline erythrocyte DHA levels and per cent change in DHA $\left(r_{s}=-0.28, p=N S\right)$.

\section{The effect of omega-3 supplementation on IHTAG and plasma postprandial metabolites (omega-3 group only)}

Eight weeks of omega-3 supplementation significantly $(p<0.05)$ decreased IHTAG by $19 \%$ (table 2$)$. The increase $(p<0.05)$ in fasting plasma glucose concentrations at 8 weeks was maintained after consumption of the mixed test meal (time-averaged $180 \mathrm{~min}$ AUC, $5.9 \pm 0.2 \mathrm{mmol} / \mathrm{L}$ vs $6.3 \pm 0.2 \mathrm{mmol} / \mathrm{L}$, baseline vs 8 weeks, $\mathrm{p}<0.05)$ and when considered over $360 \mathrm{~min}$, there was a tendency ( $p=0.058$ ) for higher fasting plasma glucose concentrations at 8 weeks compared with baseline (figure 1A). Omega-3 supplementation had no effect on postprandial plasma insulin (figure 1B) nor systemic NEFA (table 2) 
Table 1 Characteristics of study participants at baseline and 8 weeks

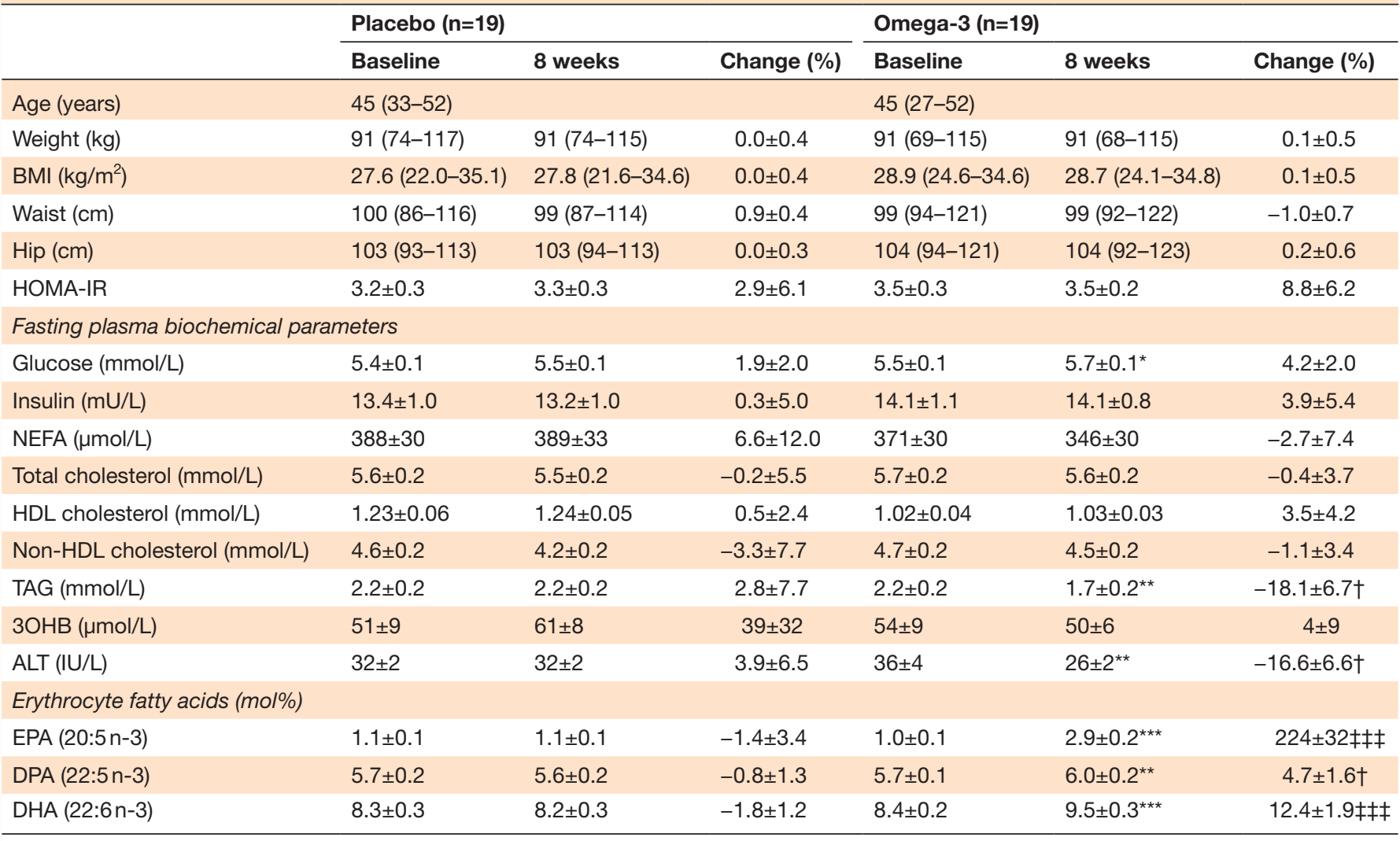

Data expressed as median (min-max) or mean \pm SEM. Change (\%) expressed as mean \pm SEM.

${ }^{*} \mathrm{P}<0.05,{ }^{* *} \mathrm{p}<0.01,{ }^{* \star *} \mathrm{p}<0.001$ baseline vs 8 weeks within the group.

$\ddagger P<0.05, \ddagger \ddagger p<0.01, \ddagger \neq \ddagger p<0.001 \%$ change in placebo vs omega-3 group.

ALT, alanine transaminase; BMI, body mass index; DHA, docosahexaenoic acid; DPA, docosapentaenoic acid; EPA, eicosapentaenoic acid; HDL, high density lipoprotein; HOMA-IR, homeostatic model assessment of insulin resistance; NEFA, nonesterified fatty acids; 3OHB, 3-hydroxybutyrate;

TAG, triacylglycerol.

concentrations. The significant $(\mathrm{p}<0.01)$ decrease in fasting plasma TAG concentrations after omega-3 supplementation were maintained over the course of the postprandial period (figure 1C), which can in part be explained by a significant decrease in fasting and postprandial VLDL-TAG concentrations (table 2). Although there was no change in VLDL-apolipoprotein (Apo)B concentrations with omega-3 supplementation, there was a significant decrease in the VLDL-TAG to VLDL-ApoB ratio, suggesting a decrease in particle size due to lower TAG content, rather than a decrease in particle number (table 2). We correlated the changes from baseline to 8 weeks for IHTAG and VLDL-TAG to VLDL-ApoB ratio and found a positive association $\left(\mathrm{r}_{\mathrm{s}}=0.54, \mathrm{p}<0.05\right)$ (online supplementary figure 2 ). There was no change in postprandial plasma 3OHB concentrations after omega-3 supplementation (table 2).

Supplementation with omega-3 FA resulted in a $30 \%$ decrease $(\mathrm{p}<0.05)$ in fasting and postprandial hepatic DNL (figure 1D). There was no association between changes in DNL (fasting or postprandial) with change in IHTAG or plasma TAG concentrations (online supplementary figure 2).

\section{The effects of omega- 3 supplementation on ${ }^{13} \mathrm{C}$ dietary FA metabolism (omega-3 group only)}

There was a significant $(\mathrm{p}<0.05)$ decrease in the appearance of ${ }^{13} \mathrm{C}$ (from dietary fat) into chylomicron-TAG but not VLDL-TAG while whole-body and hepatic ${ }^{13} \mathrm{CO}_{2}$ production significantly $(\mathrm{p}<0.05)$ increased after omega-3 supplementation (table 2). There was a significant increase in the respiratory exchange ratio (RER) between the fasting and postprandial measurement at baseline (going from $0.89 \pm 0.02$ to $0.96 \pm 0.02$, $\mathrm{p}<0.01$ ), which was not evident at 8 weeks (going from $0.90 \pm 0.01$ to $0.89 \pm 0.01, p=N S$ ). These data suggest that the fraction of ingested carbohydrate that was then synthesized into new fat via DNL would be minimal. In line with this the whole-body and hepatic $\mathrm{CO}_{2}$ data, along with the significant decrease in postprandial RER between baseline and 8 weeks, supports a shift toward FA oxidation (table 2). We calculated net substrate oxidation and found an increase $(\mathrm{p}<0.001)$ in the postprandial net fat oxidation rate $(\mathrm{g} / \mathrm{min})$ (figure $1 \mathrm{E}$ ) and a concomitant decrease $(\mathrm{p}<0.01)$ in postprandial net carbohydrate oxidation rate $(\mathrm{g} / \mathrm{min}$ ) (figure $1 \mathrm{~F}$ ) after omega-3 supplementation. 
Table 2 IHTAG content and fasting and postprandial biochemical characteristics of participants $(n=19)$ taking omega-3 FA

\begin{tabular}{|c|c|c|}
\hline & Baseline & 8 weeks \\
\hline IHTAG (\%) & $7.8 \pm 1.6$ & $6.3 \pm 1.3^{*}$ \\
\hline \multicolumn{3}{|l|}{ Fasting plasma biochemical parameters } \\
\hline VLDL-TAG $(\mu \mathrm{mol} / \mathrm{L})$ & $1335 \pm 57$ & $1069 \pm 97^{*}$ \\
\hline VLDL-ApoB (mg/dL) & $3.5 \pm 0.5$ & $4.6 \pm 0.7$ \\
\hline VLDL-TAG/VLDL-ApoB† & $34791 \pm 6600$ & $17657 \pm 2945^{\star}$ \\
\hline \multicolumn{3}{|c|}{ Postprandial plasma biochemical parameters (AUC, time-averaged) } \\
\hline Chylomicron-TAG ( $\mu \mathrm{mol} / \mathrm{L})$ & $564 \pm 70$ & $449 \pm 52$ \\
\hline VLDL-TAG $(\mu \mathrm{mol} / \mathrm{L})$ & $1546 \pm 57$ & $1330 \pm 79^{*}$ \\
\hline NEFA $(\mu \mathrm{mol} / \mathrm{L})$ & $89 \pm 21$ & $80 \pm 18$ \\
\hline $30 \mathrm{HB}(\mu \mathrm{mol} / \mathrm{L})$ & $81.5 \pm 11.3$ & $87.3 \pm 11.6$ \\
\hline \multicolumn{3}{|c|}{ Postprandial ${ }^{13} \mathrm{C}$-labeled plasma biochemical parameters (AUC, time-averaged) } \\
\hline${ }^{13} \mathrm{C}$ plasma TAG-palmitate $(\mu \mathrm{mol} / \mathrm{L})$ & $3.9 \pm 0.4$ & $3.3 \pm 0.3$ \\
\hline${ }^{13} \mathrm{C}$ chylomicron-TAG palmitate ( $\left.\mu \mathrm{mol} / \mathrm{L}\right)$ & $2.9 \pm 0.3$ & $2.0 \pm 0.2^{*}$ \\
\hline${ }^{13} \mathrm{C}$ NEFA-palmitate $(\mu \mathrm{mol} / \mathrm{L})$ & $0.43 \pm 0.04$ & $0.45 \pm 0.03$ \\
\hline${ }^{13} \mathrm{C}$ VLDL-TAG palmitate ( $\left.\mu \mathrm{mol} / \mathrm{L}\right)$ & $0.87 \pm 0.07$ & $0.79 \pm 0.05$ \\
\hline Whole-body ${ }^{13} \mathrm{CO}_{2}(\mu \mathrm{mol} / \mathrm{min})$ & $2.8 \pm 0.2$ & $3.2 \pm 0.2^{*}$ \\
\hline Hepatic ${ }^{13} \mathrm{CO}_{2}(\mu \mathrm{mol} / \mathrm{min})$ & $0.91 \pm 0.07$ & $1.0 \pm 0.06^{*}$ \\
\hline Respiratory exchange ratio & $0.96 \pm 0.02$ & $0.89 \pm 0.01^{\star *}$ \\
\hline
\end{tabular}

Data expressed as mean \pm SEM.

${ }^{*} \mathrm{P}<0.05,{ }^{* *} \mathrm{p}<0.01$ baseline vs 8 weeks.

†Molar ratio.

AUC, areas under the curve; IHTAG, intrahepatic triacylglycerol; NEFA, nonesterified fatty acids; 3OHB, 3-hydroxybutyrate; TAG,

triacylglycerol; VLDL, very low-density lipoprotein.

\section{In vitro cellular data}

To further investigate the mechanisms behind the effects observed in vivo in humans we undertook in vitro cellular studies using Huh7 cells and a FA mixture of OPL.

\section{Effect of omega- 3 on intracellular TAG content}

The addition of omega-3 (EPA+DHA) to OPL resulted in a significant decrease $(\mathrm{p}<0.01)$ in intracellular TAG content, with no change in media TAG concentration (figure 2A,B).

\section{Effect of omega-3 on FA synthesis and oxidation}

We assessed the effect of OPL and EPA+DHA with OPL only on intracellular DNL using $\left[\mathrm{U}^{13} \mathrm{C}\right]$ glucose and found a significant reduction $(\mathrm{p}<0.01)$ in the proportion of intracellular DNL (as assessed by the incorporation of ${ }^{13} \mathrm{C}$ from glucose into $16: 0\left(\left[{ }^{13} \mathrm{C}\right] 16: 0\right)$ when omega-3 $(\mathrm{EPA}+\mathrm{DHA})$ were present (figure 2C). We assessed the effects of EPA+DHA on FA oxidation by culturing cells in OPL (where $\mathrm{P}$ was $\left[\mathrm{D}_{31}\right] 16: 0$ and looking for the appearance of ${ }^{2} \mathrm{H}$ in media water) with and without EPA+DHA and found a significant $(\mathrm{p}<0.01)$ increase in media ${ }^{2} \mathrm{H}_{2} \mathrm{O}$ enrichment when cells were cultured in EPA+DHA compared with cells cultured in OPL alone (figure 2D). FAs may also undergo peroxisomal oxidation; therefore, we assessed the change in media acetate concentrations as a marker of peroxisomal FA oxidation and found a threefold increase $(\mathrm{p}<0.01)$ in the media of cells cultured with EPA+DHA compared with cells cultured in OPL alone (figure 2E). We observed a significant $(\mathrm{p}<0.05)$ increase in the concentration of $3 \mathrm{OHB}$ in media, in cells cultured in EPA+DHA compared with OPL alone (figure 2F).

We measured the relative mRNA expression of genes involved in lipogenic and oxidation pathways in Huh7 cells that had been cultured in OPL and OPL+EPA+DHA. Culturing cells with EPA+DHA resulted in significant decreases in expression of some, but not all genes. The presence of EPA+DHA significantly decreased FASN, $D G A T 2$, and SCD mRNA levels compared with OPL alone (online supplementary table 1). In contrast to our finding of increased FA oxidation when using stableisotopes, there was a significant decrease in the CPT1A mRNA levels with EPA+DHA compared with OPL alone (online supplementary table 1 ). The data for the expression of $A C A C B$ are not presented as the mRNA levels in our cell models were too low to reliably quantify.

\section{DISCUSSION}

It is often suggested that increased hepatic DNL is an underlying cause of NAFLD and/or insulin resistance, ${ }^{2}$ the latter of which at the level of the liver, leads to continued gluconeogenesis and accelerated DNL. ${ }^{36}$ Findings from animal and in vitro work show omega-3 FAs have a hepatocyte-specific effect by downregulating 
A

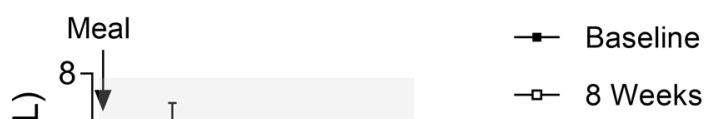

Time $\mathrm{P}<0.001$

Treatment $\mathrm{P}=0.058$

Time $x$ Treatment $P=N S$

C

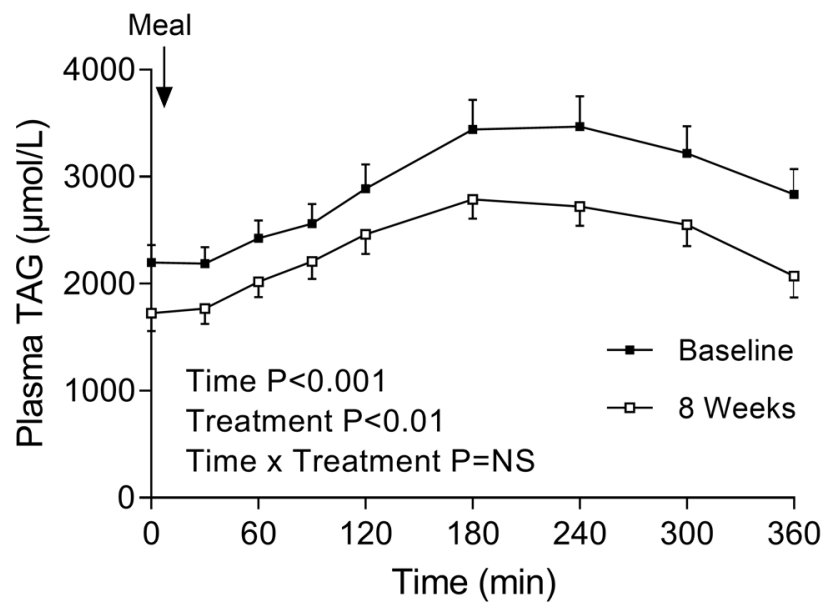

E

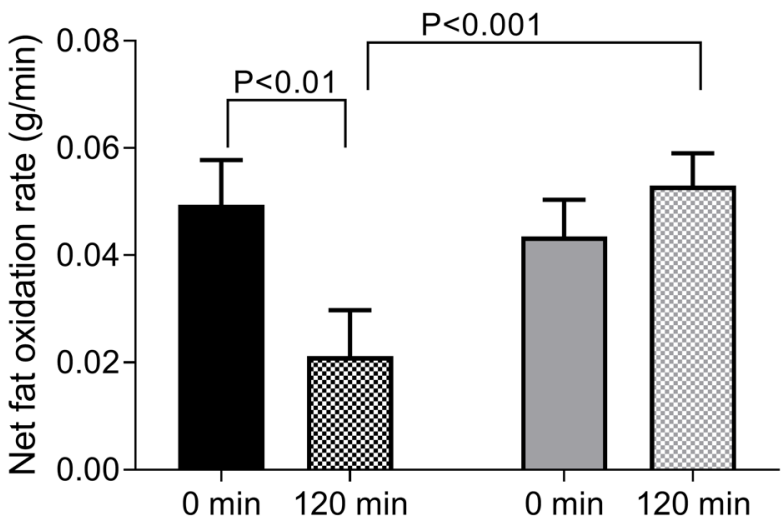

Baseline

B

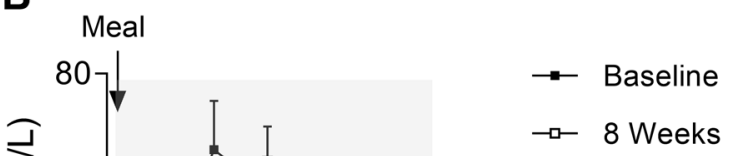

Time $\mathrm{P}<0.001$

Treatment $P=N S$

Time $\times$ Treatment $P=N S$

$\frac{\pi}{0}$

20-Time $P<0.001$
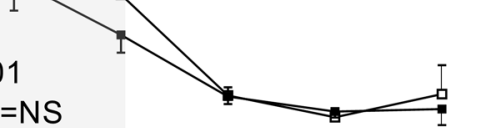

Time $x$ Treatment $P=N S$

$\begin{array}{lllllll}0 & 60 & 120 & 180 & 240 & 300 & 360\end{array}$

Time (min)

D

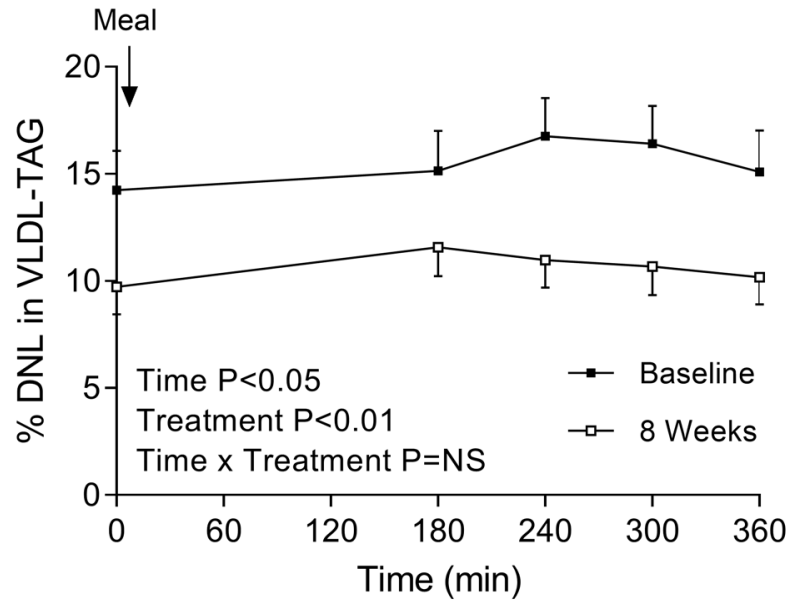

F

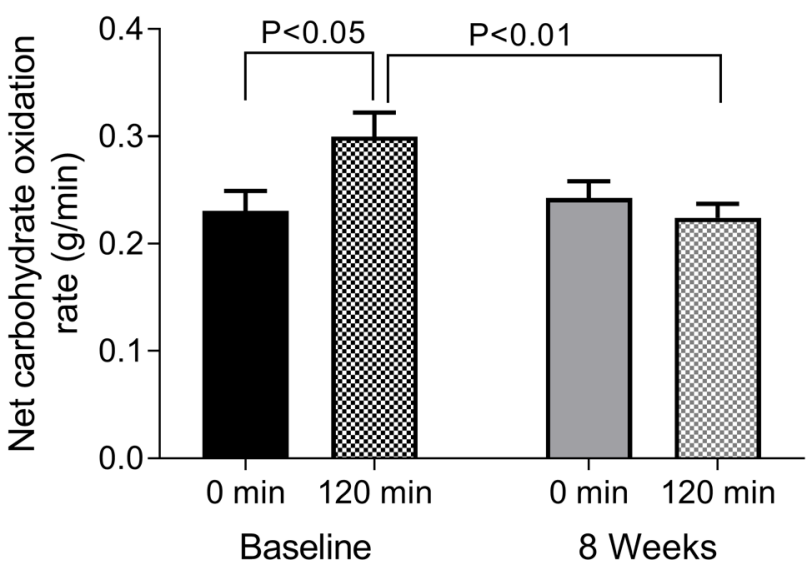

Baseline

Figure 1 The effect of omega-3 FA supplement (omega-3 FA group only) at baseline and 8 weeks on: (A) plasma glucose; (B) plasma insulin; (C) plasma TAG; (D) per cent of DNL-derived FAs in VLDL-TAG; (E) net fat oxidation (baseline and 120 min postprandial) and (F) net carbohydrate oxidation (baseline and $120 \mathrm{~min}$ postprandial). Data are presented as means \pm SEM. DNL, de novo lipogenesis; FA, fatty acid; VLDL, very low-density lipoprotein; TAG, triacylglycerol. 

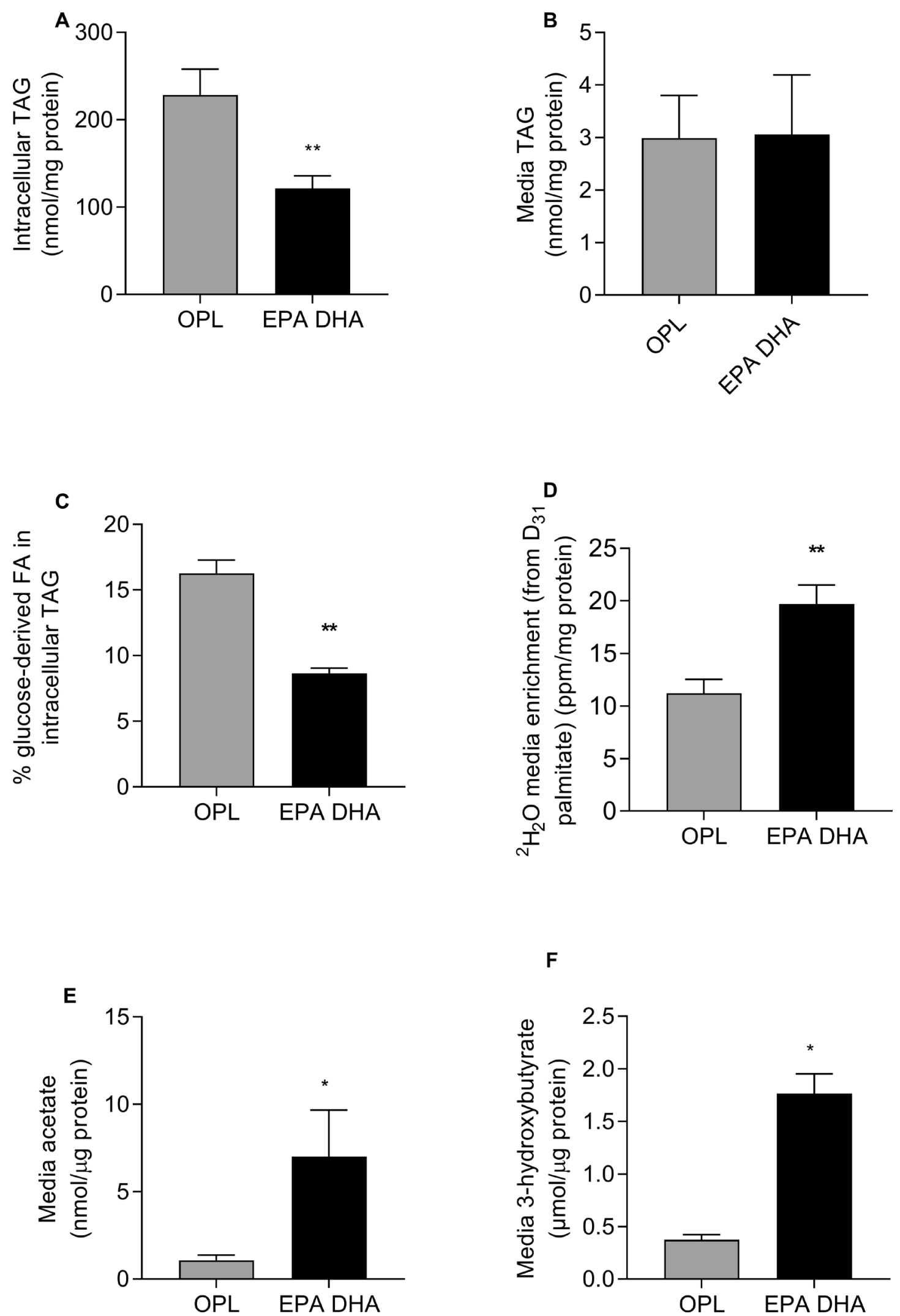

Figure 2 Huh7 cells ( $n=6$ per group) were treated with $200 \mu$ M FAs for 48 hours. Cells and media were collected and (A) intracellular TAG content and (B) media TAG content measured. Cells were treated with $200 \mu \mathrm{M}$ FAs for 48 hours with ${ }^{13} \mathrm{C}$ glucose or $D_{31}$ palmitate added to the culture media and cells and media were collected for the measurement of the effect of EPA+DHA on: (C) the relative contribution (\%) of glucose-derived DNL FAs to intracellular TAG ( $n=4)$ and (D) FA oxidation as measured by ${ }^{2} \mathrm{H}_{2} \mathrm{O}$ media enrichment (from $\mathrm{D}_{31}$ palmitate, corrected for tracer enrichment) (ppm/mg protein) in cellular media $(n=6)$. Data are presented as means \pm SEM. ${ }^{*} \mathrm{P}<0.05 ;{ }^{* *} p<0.01 ; p<0.001$ vs OPL. DNL, de novo lipogenesis; EPA DHA, OPL+EPA+DHA; FA, fatty acid; OPL, oleate, palmitate, linoleate; TAG, triacylglycerol. 
the transcription of genes in the lipogenic pathway. ${ }^{7}$ If omega-3 FAs attenuate hepatic DNL in vivo in humans, then this may, in part, explain the hypo-TAG and/or IHTAG lowering effect observed with omega-3 supplementation. Findings for the effect omega-3 FAs have on markers of glycemia and FA oxidation are inconsistent. Therefore, we used a combination of human in vivo and in vitro cellular studies, along with stable-isotope methodology, to investigate the effect of 8 weeks supplementation with omega-3 FAs (EPA+DHA) on fasting and postprandial hepatic DNL and FA oxidation. In line with previous work, we found significant decreases in fasting and postprandial plasma TAG concentrations and IHTAG content. ${ }^{17}$ Plasma ALT has been reported to be positively associated with IHTAG $^{37}$ and the observed decrease in plasma ALT levels after supplementation with omega-3 FA is consistent with a reduction in IHTAG, although a correlation between ALT and IHTAG is not always observed in studies where liver fat has decreased. ${ }^{7}$ In addition, we observed significant decreases in fasting and postprandial hepatic DNL and significant increases in dietary FA oxidation and fasting and postprandial plasma glucose concentrations. Moreover, a striking result in the current study was the reversal of a set of canonical metabolic responses to a mixed meal. At baseline, we observed the usual response to a mixed meal, with the suppression of fat oxidation, to preserve dietary FAs for storage, with dietary carbohydrate being utilized instead. After 8 weeks of omega-3 FA supplementation however, the responses to a mixed meal were remarkably different with fat oxidation significantly increasing and carbohydrate utilization significantly decreasing.

\section{Omega-3 supplementation decreases hepatic DNL}

Although it is often suggested that omega-3 FAs may lower hepatic DNL, this has not been adequately assessed in vivo in humans. In a previous pilot study of patients with NAFLD, we observed that long-term (15-18 months) supplementation with omega-3 FAs decreased fasting hepatic DNL. ${ }^{13}$ In the present study, we observed significant decreases in fasting and postprandial hepatic DNL after 8 weeks of omega-3 supplementation. The lack of response in postprandial DNL observed in the current study is notable and extends our previous observations. Hepatic DNL typically increases after consumption of a mixed meal as within the liver, insulin activates the transcription factor sterol regulatory element-binding protein 1c (SREBP-1c) which enhances the transcription of genes required for FA and TAG synthesis. ${ }^{36}{ }^{38}$ Work by McGarry $e t a l^{39}$ demonstrated that malonyl-CoA, an intermediate in the DNL pathway, was a potent inhibitor of carnitine-palmitoyl-transferase 1 . Thus, it is plausible that the physiological importance of the DNL pathway is its contribution to the regulation of FA oxidation via this mechanism, rather than its quantitative contribution to FA supply.

By assessing the effect of omega-3 FAs on glucosederived DNL in vitro in a relevant hepatocyte model (by using $\left[\mathrm{U}^{13} \mathrm{C}\right]$ glucose), we found the presence of omega-3 (EPA+DHA) attenuated the relative contribution of glucose-derived FAs to intracellular TAG. We also noted the mRNA levels of some, but not all, genes involved in the DNL pathway were attenuated. Rodent work has previously suggested that omega-3 FA supplementation leads to suppression of SREBP1-c when animals are fed a high carbohydrate/glucose diet for 7 days or 5 months. ${ }^{40} 41$ However, Xu et $a l^{41}$ noted that after one meal, despite the nuclear protein content of SREBP-1c being decreased, the amount of membrane-anchored precursor SREBP-1c and the abundance of SREBP-1c mRNA were not reduced. Our in vitro model did not recapitulate a lipogenic model that has been used in previous work, where a mixture of glucose and fructose, with no FAs, is present in the culture media. ${ }^{42}$ Rather, we cultured the cells in a mixture of nutritional substrates including a physiological mix of FAs and $11 \mathrm{mM}$ glucose and this may, in part, explain the variability in response in the mRNA levels of genes involved in the DNL pathway.

As changes in plasma TAG concentrations may be proportional to the amount of hepatic DNL, ${ }^{5}$ it is plausible the decrease in DNL observed here played a role in the observed decreases in VLDL-TAG concentrations, and IHTAG content, through shifting cellular metabolism away from esterification of FA toward oxidation. ${ }^{43}$ Although some have reported fasting hepatic DNL to be correlated with IHTAG content and VLDL-TAG secretion rate, ${ }^{4}$ we found no associations between change in IHTAG content and change in hepatic DNL. However, we did find that the change in IHTAG was positively associated with changes in the VLDL-TAG to ApoB ratio, suggesting the greater the decrease in IHTAG, the greater the decrease in TAG-rich particles in circulation. This is in line with the previous observation that there is an overproduction of large VLDL particles with increased IHTAG content in NAFLD. ${ }^{44}$ Findings from in vitro work by Fisher $e t a l,{ }^{45}$ who used a number of hepatocyte models, suggested that the loss of large, buoyant apo-B100-containing lipoproteins in the presence of omega-3 FA is due to either: (i) omega-3 FAs preventing the particles from being assembled but without allowing the unused apoB to be secreted as higher density particles or (ii) omega-3 FA permitting the assembly of buoyant particles but then selectively inducing their destruction. Further work demonstrated that the mechanism for selective destruction was via autophagosomes. ${ }^{46}$ These mechanisms may, in part, explain the decrease in TAG-rich VLDL particles, we observed in the present study with omega-3 supplementation.

\section{Supplementation with omega-3 FAs increases plasma glucose concentrations}

Studies have previously found fasting plasma glucose concentrations to increase up to $0.4 \mathrm{mmol} / \mathrm{L}$ in individuals without diabetes ${ }^{20} 47$ and over $1.0 \mathrm{mmol} / \mathrm{L}$ in individuals with $\mathrm{T}_{2} \mathrm{D}^{9}{ }^{11}$ after omega-3 supplementation. In the present study, fasting and postprandial plasma glucose concentrations significantly increased after 8 
weeks of supplementation with omega-3 FAs while having no effect on plasma insulin concentrations or markers of whole-body insulin-sensitivity (HOMA-IR). Our findings are in agreement with those of Veleba $e t a l^{11}$ who reported an increase in fasting and postprandial plasma glucose concentrations, with no change in markers of insulin sensitivity, when metformin treated T2D individuals were supplemented with omega-3 FA $(\sim 2.8 \mathrm{~g}$ $\mathrm{EPA}+\mathrm{DHA} /$ day) for 24 weeks. The authors proposed the increase in postprandial plasma glucose was due to an increase in carbohydrate and lipid availability, leading to glucose utilization being inhibited by multiple mechanisms in the Randle cycle (eg, inhibition of glucose oxidation at the level of pyruvate dehydrogenase by acetyl-CoA), reflecting peroxisome proliferator-activated receptor (PPAR) $\alpha$-mediated stimulation of FA oxidation by EPA+DHA. ${ }^{11}$ In support of this, we observed a significant decrease in whole-body net carbohydrate oxidation rates after omega-3 supplementation and this observation along with the significant decrease in postprandial hepatic DNL, may, in part, explain the increase in postprandial glucose concentrations. Moreover, it could be speculated that the increase in fasting (and postprandial) blood glucose concentrations was a consequence of shunting glucose out of the liver due to DNL being suppressed by the omega-3 FA. Evidence is sparse for the effects of omega-3 FA on intrahepatic glucose metabolism and output, in humans in vivo.

\section{Omega-3 FA supplementation increases whole-body and hepatic FA oxidation but not $30 \mathrm{HB}$ concentrations}

In contrast to others who have assessed net fat oxidation rates using indirect calorimetry, ${ }^{8}$ we did not find an increase in the fasting state; however, after consumption of the test meal, we observed a significant increase in postprandial fat oxidation rates after omega-3 supplementation. We used stable-isotope tracer methodology to assess whole-body and hepatic ${ }^{13} \mathrm{CO}_{2}$ production from recently ingested dietary fat and found both significantly increased after omega-3 supplementation. This observation may, in part, be explained by the significant decrease in postprandial hepatic DNL, which would result in cellular conditions favoring, rather than preventing, FA oxidation. ${ }^{39}$

Using stable-isotope methodology in our in vitro studies, we found increased FA oxidation to be evident only when omega-3 (EPA+DHA) were present. Moreover, we observed a significant increase in peroxisomal FA oxidation (as assessed by changes in media acetate levels) and ketogenesis (as measured by media 3OHB) with the presence of omega-3 FAs (EPA+DHA), despite no change or a decrease in the mRNA expression of genes involved in oxidation pathways. The observed increase in media 3OHB is in contrast to our observations in our in vivo study, and those of others ${ }^{13} 48$ where plasma $3 \mathrm{OHB}$ concentrations remained unchanged after omega-3 supplementation. A plausible explanation for the lack of change in plasma $3 \mathrm{OHB}$ concentrations is related to glucose sufficiency, meaning oxaloacetate was not being diverted toward gluconeogenesis and could react with acetyl-CoA to form citrate and undergo complete oxidation, rather than the acetyl-CoA being directed toward ketogenesis. ${ }^{49}$ Thus, the discrepancy we observed between the in vivo and in vitro data may be explained by glucose sufficiency in vivo, while in the in vitro work, cells were exposed $11 \mathrm{mM}$ glucose in the media glucose, by 48 hours there was virtually no detectable glucose remaining in the media. Therefore, it is plausible that had we change the media every 24 hours rather than 48 hours, the cells would have had sufficient glucose and the increase in media $3 \mathrm{OHB}$ would not have been observed.

\section{Changes in omega-3 FA status with omega-3 FA supplementation}

We found that supplementation with $1.84 \mathrm{~g} \mathrm{EPA}+1.52 \mathrm{~g}$ $\mathrm{DHA} /$ day for 8 weeks resulted in an increase of $\sim 224 \%$ for erythrocyte EPA but only a $12 \%$ increase in erythrocyte DHA, with the degree of change in erythrocyte EPA achieved being inversely associated with baseline levels for EPA but there was no association between baseline and achieved erythrocyte DHA levels. Our observation, of a far larger increase in erythrocyte EPA content than erythrocyte DHA content, is in agreement with previous studies, in which EPA and DHA was given in comparable amounts ${ }^{81050}$ or when a higher amount of DHA than EPA is consumed. ${ }^{9}$ The small change in erythrocyte DHA content compared with erythrocyte EPA content suggests a difference in bioavailability and/or metabolic handling. By supplementing with either EPA or DHA, Grimsgaard et a $\tilde{l}^{1}$ demonstrated that with DHA supplementation, the content of both EPA and DHA in serum phospholipids increased, and suggested that some of the observed increase in EPA was due to retroconversion of DHA to EPA. They also noted that with pure EPA supplementation, there was an increase in erythrocyte EPA content and a decrease in erythrocyte DHA content. ${ }^{51}$ Given these observations and the recent findings that ischemic events, including CVD, were significantly lower among individuals with elevated plasma TAG taking $4 \mathrm{~g}$ / day of a highly purified ethyl ester (Icosapent ethyl) than those taking a placebo, ${ }^{52}$ it is of interest to determine the effects of bioavailability (and mechanism of action) of both EPA and DHA. Recent evidence from the Phase III STRENGTH trial suggests that when EPA+DHA are given as carboxylic acids (Epanova), they provide no benefit in patients with mixed dyslipidemia who were at increased risk of CVD. ${ }^{53}$

\section{Limitations}

We studied only men; therefore, it would be of interest to study the effect of omega-3 supplementation on both premenopausal and postmenopausal women to determine if there are sex-specific effects. We did not assess VLDL-TAG production or clearance rates. Omega-3 supplementation has been reported to decrease VLDL ApoB production, but not catabolism ${ }^{20}$ and VLDL-TAG 
A

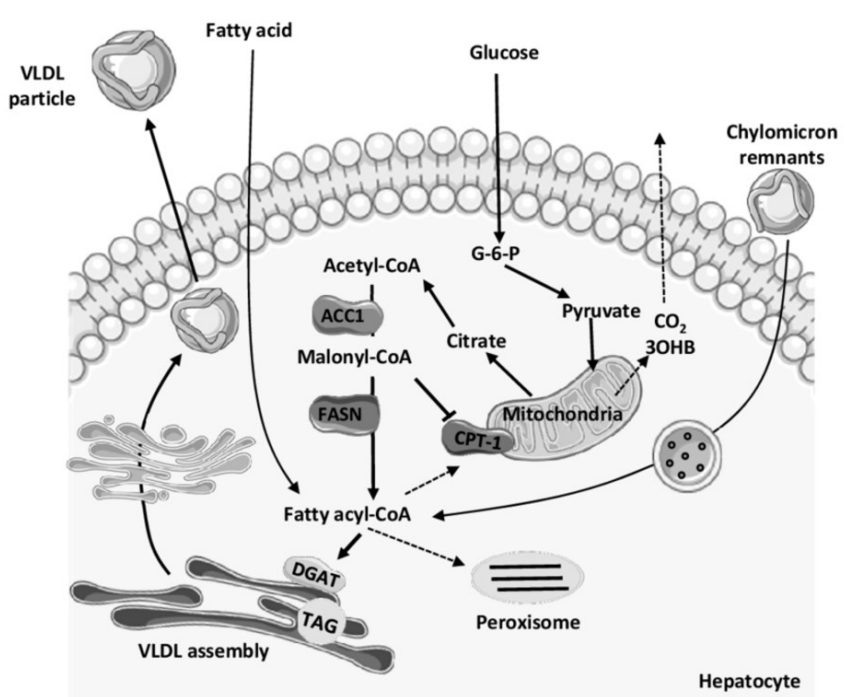

B

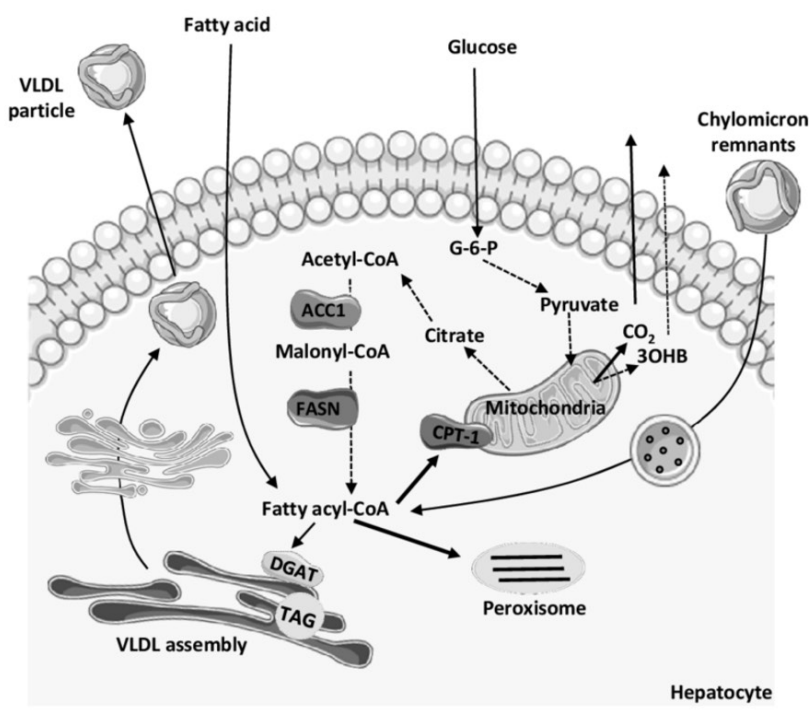

Figure 3 Overview of proposed effects of omega-3 FA on intrahepatic postprandial fatty acid metabolism. (A) Before omega-3 supplementation in the postprandial state, there was suppression of fat oxidation, while dietary carbohydrate was being used. Within the hepatocyte, glucose utilization would lead to an increase in acetyl-CoA which can then become a precursor for DNL, a pathway that is upregulated in the postprandial state. In DNL, acetyl-CoA is catalyzed by ACC1, to produce malonyl-CoA, an intermediate in the pathway, which is a potent inhibitor of CPT1. Inhibition of CPT1 leads to decreased fatty acyl-CoAs entering the mitochondria and peroxisomes to undergo oxidation. There is a decrease in the $\mathrm{CO}_{2}$ production, ketogenesis $(3 \mathrm{OHB})$ and acetate production. TAG production and VLDL assembly are maintained resulting in TAG-rich VLDL particles being secreted into systemic circulation. (B) After 8 weeks supplementation with the omega-3 FAs, EPA and DHA in the postprandial state fat oxidation is significantly increased and carbohydrate utilization is significantly decreased. There is no upregulation in the DNL pathway allowing fatty acyl-CoAs to enter the mitochondria and peroxisomes. There is an increase in hepatic $\mathrm{CO}_{2}$ production, no change in ketogenesis (3OHB) and increased acetate production. TAG production and VLDL assembly are decreased resulting in less TAG-rich VLDL particles being secreted into systemic circulation. ACC1, acetyl-CoA carboxylase; CPT-1, carnitine-palmitoyl-transferase 1; DGAT, diacylglycerol acyltransferase enzymes; DHA, docosahexaenoic acid; DNL, de novo lipogenesis; EPA, eicosapentaenoic acid; FASN, fatty acid synthase; G-6-P, glucose 6-phosphate; 3OHB, 3-hydroxybutyrate; TAG, triacylglycerol; VLDL, very low-density lipoprotein.

secretion rates $^{47}$ but has negligible effect on plasma ApoCIII concentrations, which regulate VLDL clearance. ${ }^{54}$ For logistical reasons, we assessed IHTAG and hepatic DNL and FA oxidation only in the omega-3 and not the placebo group; based on previous data; ${ }^{17}$ it is likely there would have been minimal changes in these parameters but it would be of interest to confirm this. We undertook in vitro cellular work to gain mechanistic insight; however, we cannot confirm whether both EPA and DHA were needed to have the observed effects, as the cells were exposed to both FAs; it would be of interest to determine the effects of EPA and DHA individually. Although we asked participants to maintain their habitual diet, we did not assess or control dietary intakes and thus it is plausible that the suppression in hepatic DNL resulted in a greater increase in plasma glucose concentrations in individuals who were consuming a high carbohydrate diet.

\section{CONCLUSION}

Taken together, our data demonstrate that omega-3 FAs (as EPA+DHA) are required to significantly alter intrahepatic DNL and FA oxidation, through potentially multiple intrahepatic mechanisms (figure 3) and the changes reported here may underpin decreases in plasma TAG concentrations and IHTAG content. However, with the notable decrease in fasting and postprandial hepatic DNL and postprandial carbohydrate oxidation, and signficant increase in fasting and postprandial plasma glucose concentrations, consideration is required for the long-term effects of attenuating hepatic DNL and potentially elevating circulating glucose concentrations on other intrahepatic and extrahepatic metabolic pathways.

\section{Twitter Leanne Hodson @Hodson_Group}

Acknowledgements We thank Louise Dennis, Rachel Craven-Todd and CRU staff for excellent nursing provision, Marje Gilbert for technical assistance, Sandy Humphreys for helpful statistical advice and technical assistance and Ross Milne for antibodies. We thank the volunteers from the Oxford Biobank (http://www. oxfordbiobank.org.uk) for their participation in this recall study. The Oxford BioBank and Oxford Bioresource are funded by the NIHR Oxford Biomedical Research Centre (BRC).

Contributors LH obtained funding and designed the study. LH, CJG, CP, CAC, PJG, TC and MP conducted the research. CJG, CP, PJG and LH analyzed the data. CJG, CP, FK and LH wrote the paper. FK and LH helped with data interpretation and revisions of the manuscript. LH had primary responsibility for final content. All authors read and approved the final manuscript.

Funding This study was funded by the British Heart Foundation FS/11/18/28633 and $\mathrm{FS} / 15 / 56 / 31645$ both awarded to LH. 
Disclaimer The views expressed are those of the author(s) and not necessarily those of the NIHR or the Department of Health and Social care.

Competing interests MP is a shareholder in Perspectum Diagnostics, a University of Oxford spin out company.

Patient consent for publication Not required.

Ethics approval The study was approved by Portsmouth Clinical Research Ethics Committee (12/SC/0267) and all subjects gave written informed consent.

Provenance and peer review Not commissioned; externally peer reviewed.

Data availability statement All data relevant to the study are included in the article or uploaded as supplementary information. All relevant data are included in the manuscript.

Open access This is an open access article distributed in accordance with the Creative Commons Attribution 4.0 Unported (CC BY 4.0) license, which permits others to copy, redistribute, remix, transform and build upon this work for any purpose, provided the original work is properly cited, a link to the licence is given, and indication of whether changes were made. See: https://creativecommons.org/ licenses/by/4.0/.

ORCID iDs

Fredrik Karpe http://orcid.org/0000-0002-2751-1770

Leanne Hodson http://orcid.org/0000-0002-2648-6526

\section{REFERENCES}

1 Akshintala D, Chugh R, Amer F. In: Feingold KR, Anawalt B, Boyce A, eds. Nonalcoholic fatty liver disease: the overlooked complication of type 2 diabetes. South Dartmouth (MA): Endotext, 2000.

2 Zammit VA. Hepatic triacylglycerol synthesis and secretion: DGAT2 as the link between glycaemia and triglyceridaemia. Biochem $\mathrm{J}$ 2013;451:1-12.

3 Diraison F, Moulin P, Beylot M. Contribution of hepatic de novo lipogenesis and reesterification of plasma non esterified fatty acids to plasma triglyceride synthesis during non-alcoholic fatty liver disease. Diabetes Metab 2003;29:478-85

4 Lambert JE, Ramos-Roman MA, Browning JD, et al. Increased de novo lipogenesis is a distinct characteristic of individuals with nonalcoholic fatty liver disease. Gastroenterology 2014;146:726-35.

5 Hudgins LC, Hellerstein MK, Seidman CE, et al. Relationship between carbohydrate-induced hypertriglyceridemia and fatty acid synthesis in lean and obese subjects. J Lipid Res 2000;41:595-604.

6 Balk EM, Lichtenstein AH, Chung M, et al. Effects of omega-3 fatty acids on serum markers of cardiovascular disease risk: a systematic review. Atherosclerosis 2006;189:19-30.

7 de Castro GS, Calder PC. Non-Alcoholic fatty liver disease and its treatment with n-3 polyunsaturated fatty acids. Clin Nutr 2018;37:37-55.

8 Logan SL, Spriet LL. Omega-3 fatty acid supplementation for 12 weeks increases resting and exercise metabolic rate in healthy community-dwelling older females. PLoS One 2015;10:e0144828.

9 Mostad IL, Bjerve KS, Bjorgaas MR, et al. Effects of n-3 fatty acids in subjects with type 2 diabetes: reduction of insulin sensitivity and time-dependent alteration from carbohydrate to fat oxidation. $\mathrm{Am} \mathrm{J}$ Clin Nutr 2006;84:540-50.

10 Jannas-Vela S, Roke K, Boville S, et al. Lack of effects of fish oil supplementation for 12 weeks on resting metabolic rate and substrate oxidation in healthy young men: a randomized controlled trial. PLoS One 2017;12:e0172576

11 Veleba J, Kopecky J, Janovska P, et al. Combined intervention with pioglitazone and $n-3$ fatty acids in metformin-treated type 2 diabetic patients: improvement of lipid metabolism. Nutr Metab 2015;12:52.

12 Derosa G, Cicero AFG, D'Angelo A, et al. Effects of n-3 PUFAs on fasting plasma glucose and insulin resistance in patients with impaired fasting glucose or impaired glucose tolerance. Biofactors 2016;42:316-22.

13 Hodson L, Bhatia L, Scorletti E, et al. Docosahexaenoic acid enrichment in NAFLD is associated with improvements in hepatic metabolism and hepatic insulin sensitivity: a pilot study. Eur J Clin Nutr 2017;71:973-9.

14 Karpe F, Vasan SK, Humphreys SM, et al. Cohort profile: the Oxford Biobank. Int J Epidemiol 2018;47:21.

15 Chalasani N, Younossi Z, Lavine JE, et al. The diagnosis and management of non-alcoholic fatty liver disease: practice guideline by the American gastroenterological association, American association for the study of liver diseases, and American College of gastroenterology. Gastroenterology 2012;142:1592-609.
16 Scorletti E, Bhatia L, McCormick KG, et al. Design and rationale of the WELCOME trial: A randomised, placebo controlled study to test the efficacy of purified long chainomega-3 fatty acid treatment in non-alcoholic fatty liver disease [corrected]. Contemp Clin Trials 2014;37:301-11.

17 Cussons AJ, Watts GF, Mori TA, et al. Omega-3 fatty acid supplementation decreases liver fat content in polycystic ovary syndrome: a randomized controlled trial employing proton magnetic resonance spectroscopy. J Clin Endocrinol Metab 2009;94:3842-8.

18 Hodson L, Skeaff CM, Fielding BA. Fatty acid composition of adipose tissue and blood in humans and its use as a biomarker of dietary intake. Prog Lipid Res 2008;47:348-80.

19 Chan DC, Nguyen MN, Watts GF, et al. Effects of atorvastatin and n-3 fatty acid supplementation on VLDL apolipoprotein C-III kinetics in men with abdominal obesity. Am J Clin Nutr 2010;91:900-6.

20 Chan DC, Watts GF, Mori TA, et al. Randomized controlled trial of the effect of $n-3$ fatty acid supplementation on the metabolism of apolipoprotein B-100 and chylomicron remnants in men with visceral obesity. Am J Clin Nutr 2003:77:300-7.

21 Marinou K, Hodson L, Vasan SK, et al. Structural and functional properties of deep abdominal subcutaneous adipose tissue explain its association with insulin resistance and cardiovascular risk in men. Diabetes Care 2014;37:821-9.

22 Hodson L, McQuaid SE, Karpe F, et al. Differences in partitioning of meal fatty acids into blood lipid fractions: a comparison of linoleate, oleate, and palmitate. Am J Physiol Endocrinol Metab 2009;296:E64-71.

23 Banerjee R, Pavlides M, Tunnicliffe EM, et al. Multiparametric magnetic resonance for the non-invasive diagnosis of liver disease. Hepatol 2014;60:69-77.

24 Pramfalk C, Pavlides M, Banerjee R, et al. Fasting plasma insulin concentrations are associated with changes in hepatic fatty acid synthesis and partitioning prior to changes in liver fat content in healthy adults. Diabetes 2016;65:1858-67.

25 Hodson L, Bickerton AST, McQuaid SE, et al. The contribution of splanchnic fat to VLDL triglyceride is greater in insulin-resistant than insulin-sensitive men and women: studies in the postprandial state. Diabetes 2007:56:2433-41.

26 Chong MF-F, Fielding BA, Frayn KN. Mechanisms for the acute effect of fructose on postprandial lipemia. Am J Clin Nutr 2007;85:1511-20.

27 Hems R, Saez GT. Equilibration of metabolic CO2 with preformed $\mathrm{CO} 2$ and bicarbonate. An unexpected finding. FEBS Lett 1983;153:438-40.

28 Kloppenburg WD, Wolthers BG, Stellaard F, et al. Determination of urea kinetics by isotope dilution with [13C]urea and gas chromatography-isotope ratio mass spectrometry (GC-IRMS) analysis. Clin Sci 1997:93:73-80.

29 Bergouignan A, Schoeller DA, Votruba S, et al. The acetate recovery factor to correct tracer-derived dietary fat oxidation in humans. Am J Physiol Endocrinol Metab 2008;294:E645-53.

30 Müller MJ. Hepatic fuel selection. Proc Nutr Soc 1995;54:139-50.

31 Semple RK, Sleigh A, Murgatroyd PR, et al. Postreceptor insulin resistance contributes to human dyslipidemia and hepatic steatosis. J Clin Invest 2009;119:315-22.

32 Gunn PJ, Green CJ, Pramfalk C, et al. In vitro cellular models of human hepatic fatty acid metabolism: differences between Huh7 and HepG2 cell lines in human and fetal bovine culturing serum. Physiol Rep 2017;5:e13532.

33 Collins JM, Neville MJ, Pinnick KE, et al. De novo lipogenesis in the differentiating human adipocyte can provide all fatty acids necessary for maturation. J Lipid Res 2011;52:1683-92.

34 Law L-K, Tang NL-S, Hui J, et al. A novel functional assay for simultaneous determination of total fatty acid beta-oxidation flux and acylcarnitine profiling in human skin fibroblasts using $(2) \mathrm{H}(31)$ palmitate by isotope ratio mass spectrometry and electrospray tandem mass spectrometry. Clin Chim Acta 2007;382:25-30.

35 Matthews DR, Hosker JP, Rudenski AS, et al. Homeostasis model assessment: insulin resistance and beta-cell function from fasting plasma glucose and insulin concentrations in man. Diabetologia 1985;28:412-9.

36 Brown MS, Goldstein JL. Selective versus total insulin resistance: a pathogenic paradox. Cell Metab 2008;7:95-6.

37 Maximos M, Bril F, Portillo Sanchez P, et al. The role of liver fat and insulin resistance as determinants of plasma aminotransferase elevation in nonalcoholic fatty liver disease. Hepatology 2015;61:153-60.

$38 \mathrm{Wu}$ X, Chen K, Williams KJ. The role of pathway-selective insulin resistance and responsiveness in diabetic dyslipoproteinemia. Curr Opin Lipidol 2012;23:334-44. 
39 McGarry JD, Mannaerts GP, Foster DW. A possible role for malonyl-CoA in the regulation of hepatic fatty acid oxidation and ketogenesis. J Clin Invest 1977;60:265-70.

40 Kim HJ, Takahashi M, Ezaki O. Fish oil feeding decreases mature sterol regulatory element-binding protein 1 (SREBP-1) by down-regulation of SREBP-1c mRNA in mouse liver. A possible mechanism for down-regulation of lipogenic enzyme mRNAs. J Biol Chem 1999;274:25892-8.

$41 \mathrm{Xu} \mathrm{J}$, Cho H, O'Malley S, et al. Dietary polyunsaturated fats regulate rat liver sterol regulatory element binding proteins- 1 and -2 in three distinct stages and by different mechanisms. J Nutr 2002;132:3333-9.

42 Huang D, Dhawan T, Young S, et al. Fructose impairs glucoseinduced hepatic triglyceride synthesis. Lipids Health Dis 2011;10:20.

43 Lewis GF, Carpentier A, Adeli K, et al. Disordered fat storage and mobilization in the pathogenesis of insulin resistance and type 2 diabetes. Endocr Rev 2002;23:201-29.

44 Adiels M, Taskinen M-R, Packard C, et al. Overproduction of large VLDL particles is driven by increased liver fat content in man. Diabetologia 2006;49:755-65.

45 Fisher EA, Pan M, Chen X, et al. The triple threat to nascent apolipoprotein B. Evidence for multiple, distinct degradative pathways. J Biol Chem 2001;276:27855-63.

46 Fisher EA, Williams KJ. Autophagy of an oxidized, aggregated protein beyond the ER: a pathway for remarkably late-stage quality control. Autophagy 2008;4:721-3.

47 Wong ATY, Chan DC, Ooi EMM, et al. Omega-3 fatty acid ethyl ester supplementation decreases very-low-density lipoprotein triacylglycerol secretion in obese men. Clin Sci 2013;125:45-51.
48 Delarue J, Couet C, Cohen R, et al. Effects of fish oil on metabolic responses to oral fructose and glucose loads in healthy humans. Am J Physiol 1996;270:E353-62.

49 Laffel L. Ketone bodies: a review of physiology, pathophysiology and application of monitoring to diabetes. Diabetes Metab Res Rev 1999;15:412-26.

50 Blonk MC, Bilo HJ, Nauta JJ, et al. Dose-Response effects of fish-oil supplementation in healthy volunteers. Am J Clin Nutr 1990;52:120-7.

51 Grimsgaard S, Bonaa KH, Hansen JB, et al. Highly purified eicosapentaenoic acid and docosahexaenoic acid in humans have similar triacylglycerol-lowering effects but divergent effects on serum fatty acids. Am J Clin Nutr 1997;66:649-59.

52 Bhatt DL, Steg PG, Miller M, et al. Cardiovascular risk reduction with Icosapent ethyl for hypertriglyceridemia. N Engl J Med 2019;380:11-22.

53 AstraZeneca. Independent data monitoring Committee has recommended to discontinue the trial as Epanova is unlikely to demonstrate a benefit to patients 2020. Available: https://www. astrazeneca.com/content/astraz/media-centre/press-releases/ 2020/update-on-phase-iii-strength-trial-for-epanova-in-mixeddyslipidaemia-13012020.html [Accessed 13 Jan 2020].

54 Mendivil CO, Zheng C, Furtado J, et al. Metabolism of verylow-density lipoprotein and low-density lipoprotein containing apolipoprotein C-III and not other small apolipoproteins. Arterioscler Thromb Vasc Biol 2010;30:239-45. 